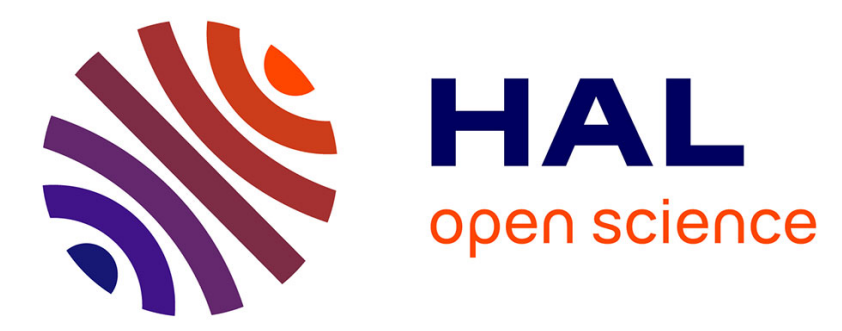

\title{
Texture analysis of silicon with an heterogeneous morphology used for the photovoltaic conversion by neutron diffraction
}

P. Andonov, P. Dervin, C. Esling

\section{- To cite this version:}

P. Andonov, P. Dervin, C. Esling. Texture analysis of silicon with an heterogeneous morphology used for the photovoltaic conversion by neutron diffraction. Revue de Physique Appliquée, 1987, 22 (7), pp.603-612. 10.1051/rphysap:01987002207060300 . jpa-00245583

\section{HAL Id: jpa-00245583 https://hal.science/jpa-00245583}

Submitted on 1 Jan 1987

HAL is a multi-disciplinary open access archive for the deposit and dissemination of scientific research documents, whether they are published or not. The documents may come from teaching and research institutions in France or abroad, or from public or private research centers.
L'archive ouverte pluridisciplinaire HAL, est destinée au dépôt et à la diffusion de documents scientifiques de niveau recherche, publiés ou non, émanant des établissements d'enseignement et de recherche français ou étrangers, des laboratoires publics ou privés. 
Classification

Physics Abstracts

$61.10 \mathrm{~F}-61.14 \mathrm{~F}$

\title{
Texture analysis of silicon with an heterogeneous morphology used for the photovoltaic conversion by neutron diffraction
}

\author{
P. Andonov, P. Dervin (*) and C. Esling $\left(^{+}\right)$ \\ Laboratoire de Magnétisme du CNRS, Bellevue, 1, place A.-Briand, 92195 Meudon Principal Cedex, France \\ (*) Laboratoire Léon Brillouin, CNRS-CEA Saclay, 91191 Gif-sur-Yvette Cedex, France \\ $\left(^{+}\right)$Laboratoire de Métallurgie Structurale, Faculté des Sciences, Ile du Saulcy, 57045 Metz Cedex, France
}

(Reçu le 2 octobre 1986, révisé le 12 février 1987, accepté le 27 mars 1987)

\begin{abstract}
Résumé. - L'étude a porté sur un matériau polycristallin massif obtenu par refroidissement rapide dans un gradient thermique selon le procédé de Bridgman sans germe. La texture en volume, étudiée par diffraction neutronique en transmission, est caractérisée à partir des figures de pôles directes relatives aux quatre familles de plans cristallographiques : (400), (220), (111) et (113). Un mode d'exploration précis a été défini pour ce matériau hétérogène. Le calcul de la Fonction de Distribution des Orientations Cristallines ne peut se faire qu'après utilisation d'une technique de lissage des densités de pôles.

Abstract. - Polycrystalline silicon ingots, obtained by rapid solidification according to Bridgman method without seed crystal, are studied. The texture in the bulk, determined using the transmission neutron diffraction, is characterized from the direct pole figures plotted for the four families of the low indices lattice planes (400), (220), (111) and (113). An accurate exploring mode has been defined for this heterogeneous material. The use of smoothing computer programs on the pole densities is necessary to calculate the Orientation Distribution Function (O.D.F.) by spherical harmonics analysis.
\end{abstract}

\section{Introduction.}

In order to lower the production cost of solar cells, the Research Laboratories of C.G.E. at Marcoussis have initiated a program of research on growth techniques of polycristalline silicon ingots in which thin wafers are sawn to form the sensitive sheets of the cells. Rapid directional solidification of silicon in carbon crucible was achieved by a variant of the Bridgman process seedless. At the beginning the method was applied with $0.5-1 \mathrm{~kg}$ silicon charges [1]. In the so obtained ingots, several domains are observed with different crystallizations. In the middle, an axially columnar structure is produced by the grains growing in the alignment with the temperature gradient. On the edges, the structure is dominated by the grain nucleation at the crucible walls ; a radial alignment is observed with a dendritic structure. Between these two previous zones, domains exist with transition and intermediary structures. It is interesting to know if a marked solidification texture is present in the bulk and what correlations exist between crystallographic orientations and elaboration parameters.

The increasing quality of ingots with their size and the new process « Polix » with crucible reusing [2] have decided Photowatt S.A. [3] to begin the industrial development of $15-20 \mathrm{~kg}$ blocks. The vertical section of these ingots shows an important domain with well developed almost vertical grains ; the others structural zones taking up only a small relative volume. In the horizontal section, the grain sections have any shapes with sizes often larger than $1 \mathrm{~cm}^{2}$. Solar cells are realized using $10 \times 10 \mathrm{~cm}^{2}$ wafers, cut out of ingot perpendicularly to growth axis, which led to photovoltaic efficiency $\eta \simeq 11 \%$ under AM1 conditions, starting of «electronic grade " silicon. The orientation statistic at the wafer surface and the grain size would be limiting factors of this efficiency. It is interesting to determine the 
crystallographic orientations of surface planes for all crystallites included in the sheet and to correlate them with the conversion efficiency.

The texture investigations in the bulky ingot and at the wafer surface require two different procedures. In the first case a transmission exploration is necessary to take into account all crystallites of the studied volume. In the second case, a rapid reflection exploration should be used to control the large complete surface. Previously an electrochemical method had been developed very rapid but without great precision [4].

To mend it, a reflection diffraction method has been tested using a new spectrometer with large sample holder.

We present in this paper only the first diffraction method applied to the particular problem relative to this silicon: heterogeneous material resulting of a rapid solidification.

\section{Solidification texture in the bulk. Why the neutron diffraction?}

The texture of a polycrystalline material is the orientation distribution of its crystallites with respect to a sample fixed reference system i.e. in the silicon ingots studied in this work : the longitudinal growth axis and two transverse directions perpendicular to the lateral faces of the square section block.

Orientation distribution of crystals in a given specimen contains valuable informations resulting of its crystallization mechanisms and can be used to control the anisotropy of the material. But to be representative of the bulk material, the texture measurement has to be evaluated from a grain number large enough to obtain correct statistics and from a sufficient volume to integrate possible inhomogeneities.

The X-ray diffraction technique is badly adapted to the measure of the complete Pole Figure (P.F.) in this material. Because its high absorption of X-rays, only a thin surface layer is investigated, the crystallite number is insufficient and measurements both by transmission and reflection are necessary.

Some of these difficulties are suppressed by using the diffraction of neutrons $[5,6]$ which are very weakly absorbed by silicon. The great cross section of the incident beam allows the study of large size sample and so a better crystallite statistics is obtained. The complete P.F., relative to the total sample volume, are obtained directly from data gained in transmission only, without absorption correction. Moreover, with its high symmetry (cubic diamond) and its relative small lattice parameter, the Bragg reflections obtained with silicon for the four lowest indice lattice planes are well separated without overlapping peaks.
Nevertheless a double problem subsists. Firstly the crystallite statistics is still very weak when a main part of the sample volume is occupied only by few large grains. Secondly the good crystalline perfection of some individual grains conducts to intense and very narrow reflections.

An accurate texture experiment is described to obtain precise P.F. Then after rapid theoretical recalls, we report the smoothing methods applied to obtain the computation of the three dimensional O.D.F.

\section{Neutron diffraction experiments in the transmis- sion mode.}

The experiments have been carried out on the conventional «four circles " goniometer at the reactor «Orphée » of the C.E.N. Saclay (Laboratoire C.E.A.-C.N.R.S. Léon Brillouin). A flux of monochromatic neutrons is provided by the neutron guide G5 and a pyrolytic graphite monochromator of which the (0002) planes select the wavelength $\lambda=1.68 \AA$. The maxima divergencies of the incident beam are as follows :

- horizontal divergence : $\delta_{1}=1.40 \pm 0.05^{\circ}$

- vertical divergence : $\delta_{\mathrm{h}}=3.00 \pm 0.10^{\circ}$.

Height and width of the detector receiving slit can be adjusted independently and the sample-detector distance can be varied.

The sample is mounted on the Euler cradle. It is rotated about its axis : azimuthal rotation $\Phi$ with $0 \leqslant \Phi \leqslant 2 \pi$ and this axis can be rotated in the cradle plane : polar rotation $\chi$ with $0 \leqslant \chi \leqslant \pi / 2$. (see Fig. 1).

The complete P.F. is explored by circular scanning mode with constant azimuthal and polar steps. The step values $\Delta \Phi$ and $\Delta \chi$ have to be evaluated accurately to preserve the validity of texture data. They depend on the angular resolving power which is defined by the angular ranges $\Delta \Phi^{\prime}$ and $\Delta \chi^{\prime}$ through which a single crystal can be rotated without the reflected beam leaving the receiving slit. This resolution depends on monochromator characteristics, incident and diffracted beam divergencies, sample size and device geometry. A $\Delta \Phi^{\prime}$ limit can be estimated from the half maximum width in $2 \theta$ of the Bragg reflections. With a heterogeneous material, as the silicon studied in this work, the probability of counting the large almost perfect crystallites is rather small taking into account the small horizontal divergence of neutron beam. To avoid the loss of their diffracted intensities the exploration was made in very small steps $\Delta \Phi \cong \Delta \Phi^{\prime}$; but this is very time consuming. A 


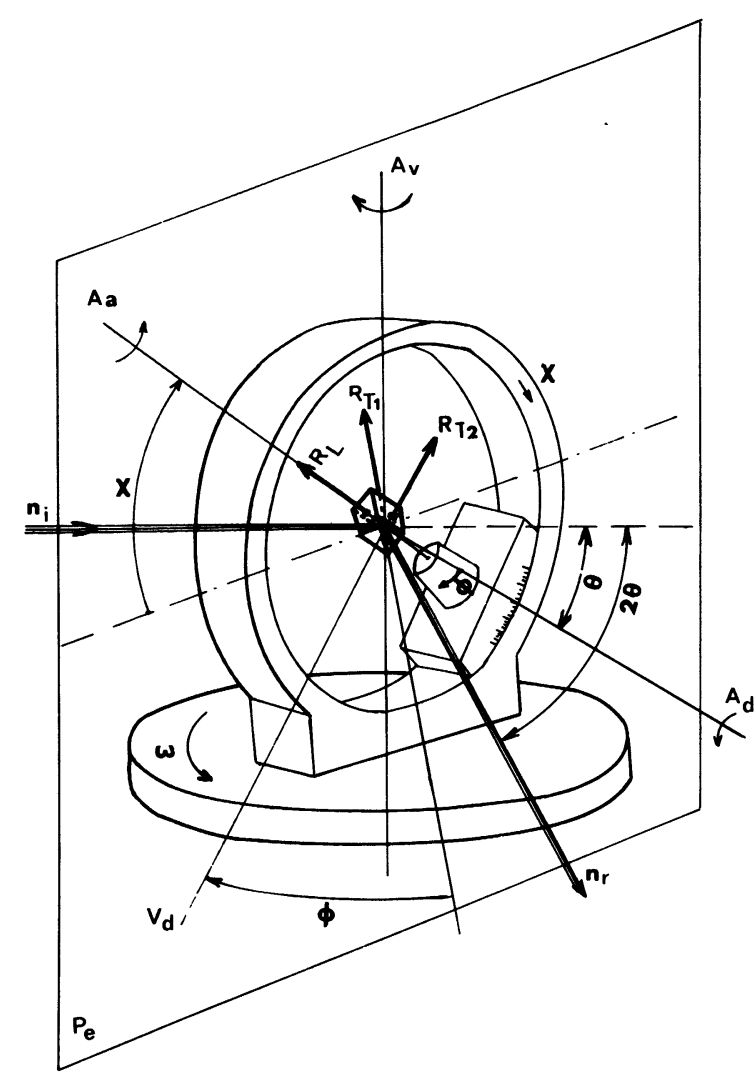

Fig. 1. - Schematic view of the « four circles » goniometer $A_{a}$ : azimuthal rotation axis ; $A_{d}$ : polar rotation axis.

more important value is allowed for $\Delta \chi^{\prime}$ by the vertical divergence; the polar step $\Delta \chi$ is chosen equal to $\Delta \chi^{\prime}$. To obtain a correct exploration, the successively explored spheric zones have to be adjacent [7]. With a parallel beam

$$
\Delta \chi=H /\left(2 R \sin \theta_{h k l}\right)
$$

The $\Delta \chi$ step imposes the ratio

$$
H / R=\left(\lambda / d_{h k l}\right) \cdot \Delta \chi
$$

where $H$ is the height of the detector receiving slit, $R$ the sample-detector distance, $d_{h k l}$ the interplanar distance.

The respective variations of $H$ and $R$ are limited by the sample size, the beam divergence, the declination $\chi$ value and the different fixed diaphragms located in the diffracted beam. The maximum divergence varies with the sample orientation in the incident beam. The $R$ limits are calculated with the different diaphragms ; the lowest value is retained. The exploration mode in stereographic projection is shown figure 2 . Some additional characteristics of the experiment are given :

- sample cutting : cubic volume equal to $1 \mathrm{~cm}^{3}$, sample faces parallel with the ingot faces in the $\Phi$ rotation the sample axis is chosen parallel to the ingot axis

- effective maxima divergence with cube of $a=10 \mathrm{~mm}: \quad \delta_{1}^{\prime}=0.95 \pm 0.05^{\circ} \quad$ and $\quad \delta_{\mathrm{h}}^{\prime}=$ $2.20 \pm 0.10^{\circ}$

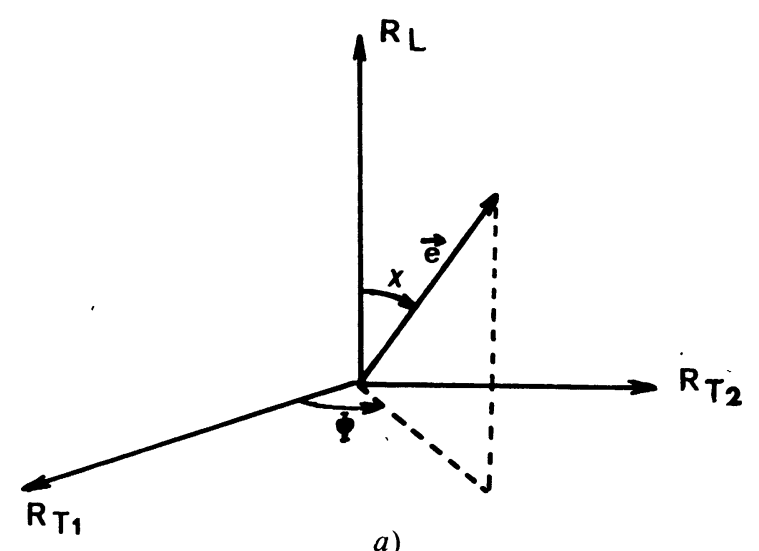

a)

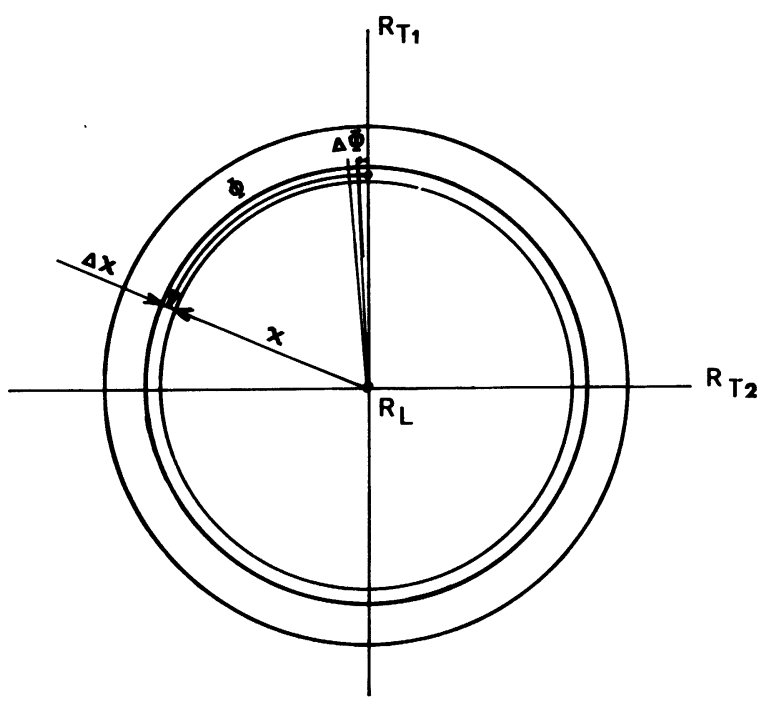

b)

Fig. 2. - Exploration mode and angular position $(\chi, \Phi)$ in stereographic projection.

$$
\left.\begin{array}{l}
\text { - azimuthal step } \Delta \Phi=0.5^{\circ} \\
\text { - polar step } \Delta \chi=3^{\circ}
\end{array}\right\}
$$

i.e. 22320 steps for a complete P.F.

- record time per spectrum $\cong 60 \mathrm{~h}$,

- counting statistics $\leqslant 2 \%$ except in the background.

\section{Theoretical analysis.}

The texture data of one specimen have been registered for the four P.F.: (111), (220), (311) and (400). The initial evaluation of the texture consists of the output and stereographic plot of the experimental pole figures. In these figures, the level value of $d=1$ corresponds to the density of a random sample. A qualitative texture could be evaluated by the « ideal orientations » i.e. the set of « equivalent orientations » of monocrystals which would give poles at the maxima of the observed pole concentrations. A computer program was written which searchs for the peak maxima in all the stereographic 
projection; their coordinates and their density values are classified in terms of crystalline orientation and grain size. So it is possible to obtain a first rough estimation of volume fractions which diffract at these maxima.

Information about positions and intensities of peak maxima is the least requirement for a first qualitative description but a complete quantitative and comprehensible knowledge of the texture is given by the three dimensional O.D.F. in the Euler space [8-9].

If $F(g)$ is the O.D.F. relative to the orientation $g$, the volumic fraction of grains with orientation $g \pm \mathrm{d} g$ in the explored total volume $V_{0}$ is proportional to $F(g)$.

$$
\mathrm{d} V / V_{0}=K \cdot F(g) \cdot \mathrm{d} g
$$

The O.D.F. is computed by the resolution of the fundamental equation which connects the experimental physical informations (pole densities $\left.q_{h k l}(\mathbf{e})\right)$ and the wanted distribution function :

$$
q_{h k l}(\mathbf{e})=\frac{1}{2 \pi} \int_{0}^{2 \pi} F(g) \mathrm{d} \gamma
$$

where $\gamma$ is the rotation about the normal to the reflecting lattice planes. The details of the computation methods have been largely developed elsewhere $[10,11]$.

In this work, O.D.F. calculations have been made taking into account a triclinic sample symmetry and the cubic symmetry of the silicon crystalline lattice. In these conditions, it is possible theoretically, with four complete P.F., to calculate O.D.F. by the series expansion method up to the order $\lambda_{\max }=34$ with an overdetermined system. In practice, the resolution of the spherical harmonic analysis is not sufficient to take into account the discontinuities and the great values of the pole densities even if $\lambda_{\max }=34$. That is why the application of the method with the raw experimental data might only give incorrect O.D.F. evaluation associated to prohibitive errors. Before any computation, pole figure smoothing programs had to be adjusted to reduce the intensity discontinuities.

4.1. Smoothing Routines. - At once texture data are regrouped. On every $\chi$ circle, the data obtained from 10 successives $\Delta \Phi$ steps are summed up and the sum allocated to their barycentre. This first smoothing of rough intensities is not sufficient and more drastic methods are necessary to reduce the important discontinuities. Two different smoothing programs have been cheked.

In the program described by Welch [12], at each data point a Gaussian function is associated ; fitted at this point, so that the maximum corresponds to the measured intensity $I_{i}$; the chosen half width $\phi_{0}$ can be varied to give different degrees of smoothing. Then the intensity assigned at the point $\mathbf{e}_{0}$ is given by :

$$
\left\langle I_{0}\right\rangle=\frac{1}{n_{\mathrm{e}}} \sum_{i \in \text { circle }} I_{i} \mathrm{e}^{-\left(\phi_{i} / \phi_{0}\right)^{2}}
$$

where $n_{\mathrm{e}}$ is the number of data points contained in the pole sphere part which is delimited by the circle centred about $\mathbf{e}_{0}$ with a radius of $3 \phi_{0}$. So the $\phi_{0}$ value affects the peak broadening, but also the amount of peaks taken into account in the averaged intensity. On the other hand, if all data points keep equal weight, the allowed intensity in the central region would be artificially increased. The applied weighting factor is the solid angle corresponding to each data point, it is expressed as :

$$
\left[\cos \left(x-\frac{\Delta x}{2}\right)-\cos \left(\chi+\frac{\Delta \chi}{2}\right)\right]
$$

for an equiangular scanning (in $\chi$ and $\Phi$ ).

In the second program used in this work, each «Dirac » peak is also fitted by a Gaussian function but the intensity is averaged about the first and the second neighbouring points, i.e. only nine intensity data

$$
\left\langle I_{0}\right\rangle=\frac{1}{9} \sum_{i=1}^{9} I_{i} \mathrm{e}^{-\left(\phi_{i} / \phi_{0}\right)^{2}} .
$$

In the both programs, the values at $\chi=0^{\circ}$ and $\chi=90^{\circ}$ require a specific correction using the centro symmetrical equivalent points of P.F.

The O.D.F. can be computed from these smoothed data. The computation has been made using the Bunge's formalism and with the expansion order $\lambda_{\text {max }}=34$.

Nevertheless, the use of the smoothing routines must be accompanied by critical judgement and constant comparison of the original input P.F. data with recalculated P.F. data to avoid falsified results (see Fig. 3).

\section{Results.}

Several samples have been studied. A qualitative description of material was obtained from the experimental pole figures (111), (220), (311) and (400). A tendency to axial symmetry can be observed in the ingots about the longitudinal growth axis. In the small ingots, marked texture variations are observed in the different crystallization zones. Figures $4 a, b$, c present the P.F. (400) plotted from samples taken in the dendritic, columnar and intermediary zones respectively. The pole distribution is random around the projection axis ( $\Phi$ exploration) but it changes with the polar orientation. 


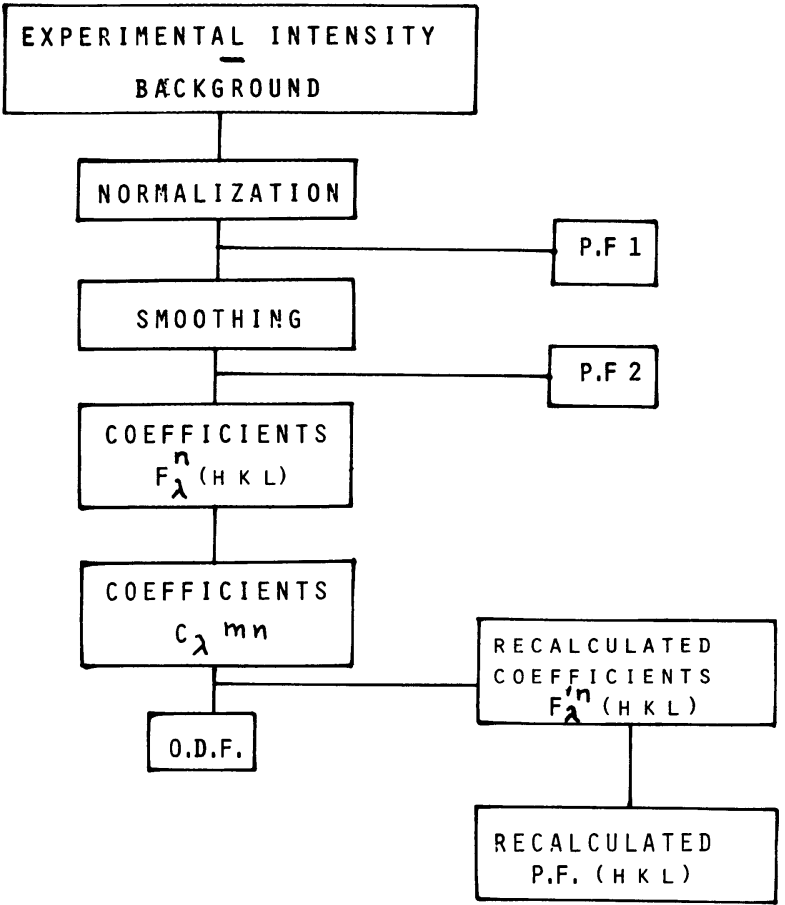

Fig. 3. - Process chart of data analysis.

In the large ingots the zone differentiation appears weakly. The P.F. (400) (see Fig. 4d), plotted from a sample taken in the low central part of a $20 \mathrm{~kg}$ block, shows an uniform distribution like the observed one in the intermediary domain of a small ingot (Fig. 4c to compare with Fig. 4d). But the smaller pole number and the higher intensity maxima indicate a larger grain size.

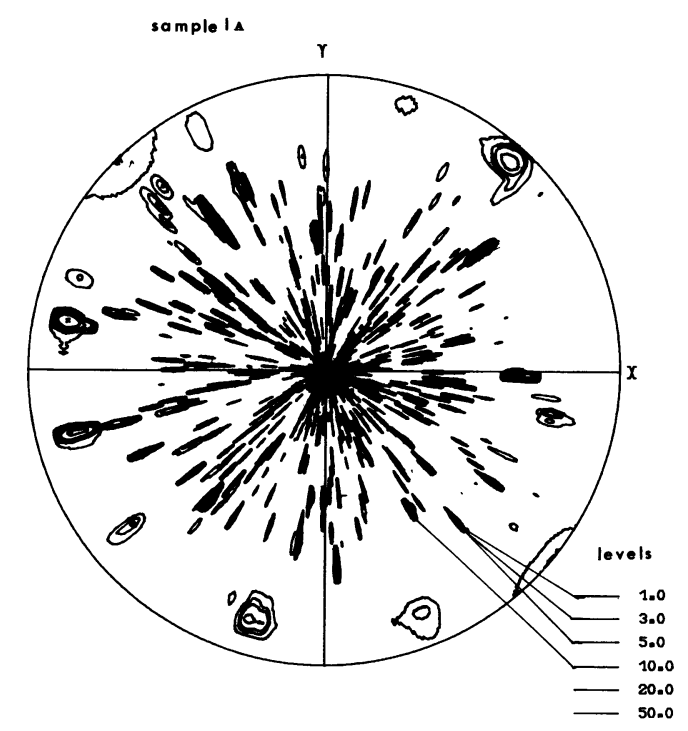

(1)

Fig. 4. - Pole Figure (400) plotted for different samples taken in :

- small ingots (C.G.E.) : a) $\mathrm{I}_{\mathrm{A}}$, dendritic zone ;

b) $\mathrm{I}_{B}$, columnar zone ; c) $\mathrm{II}_{B}$, intermediary zone

- $20 \mathrm{~kg}$ block (Photowatt): d) $\mathrm{III}_{\mathrm{B}}$, central zone.

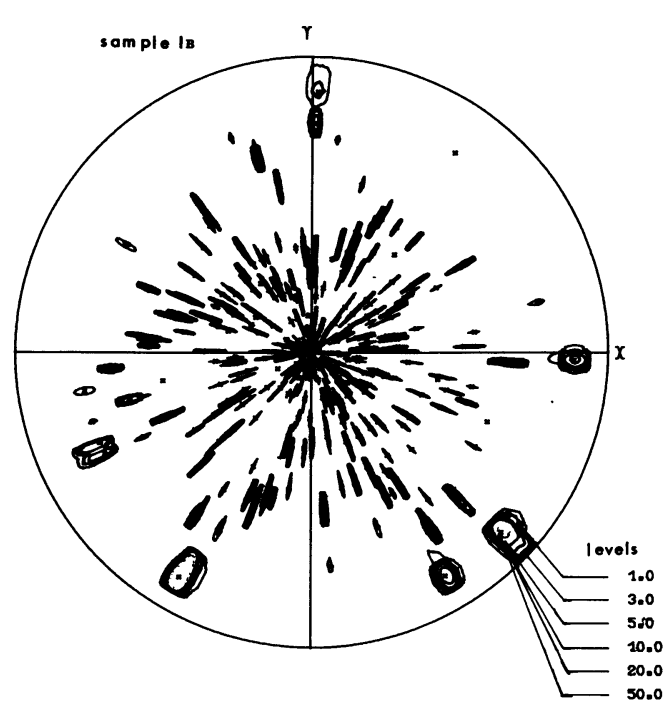

b)

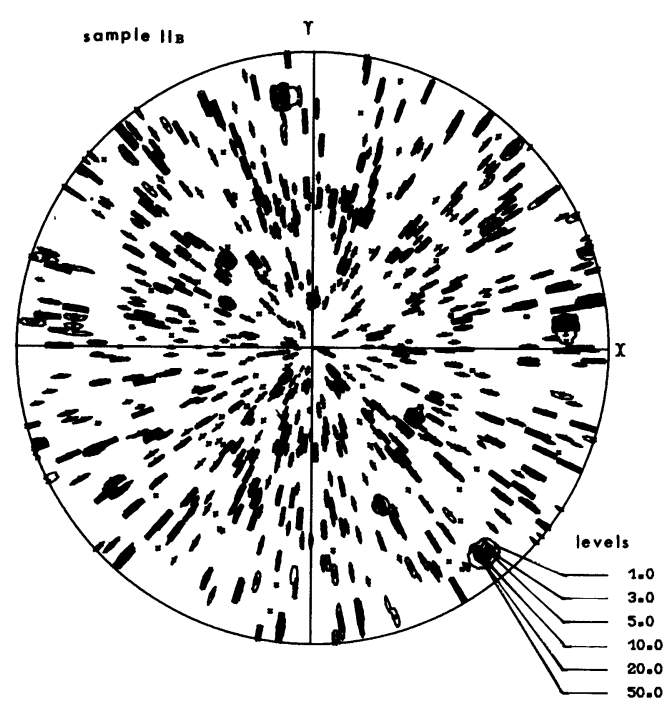

c)

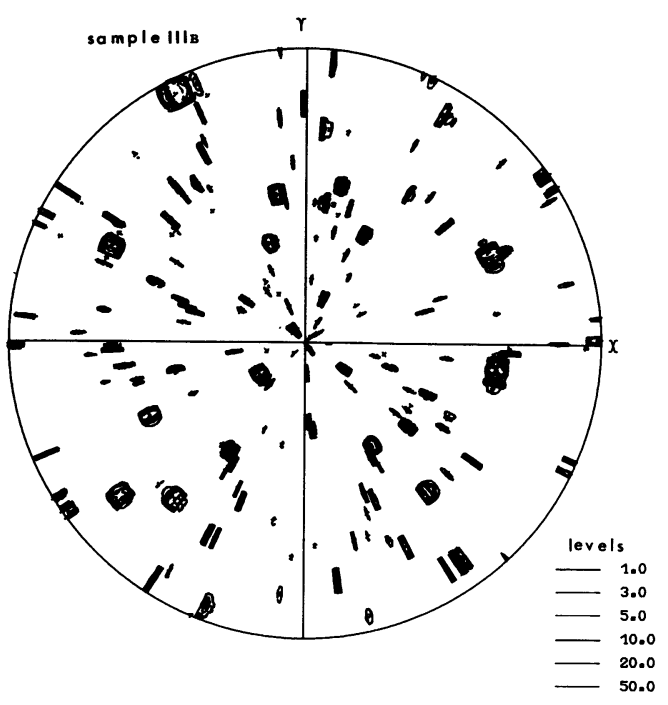

d) 


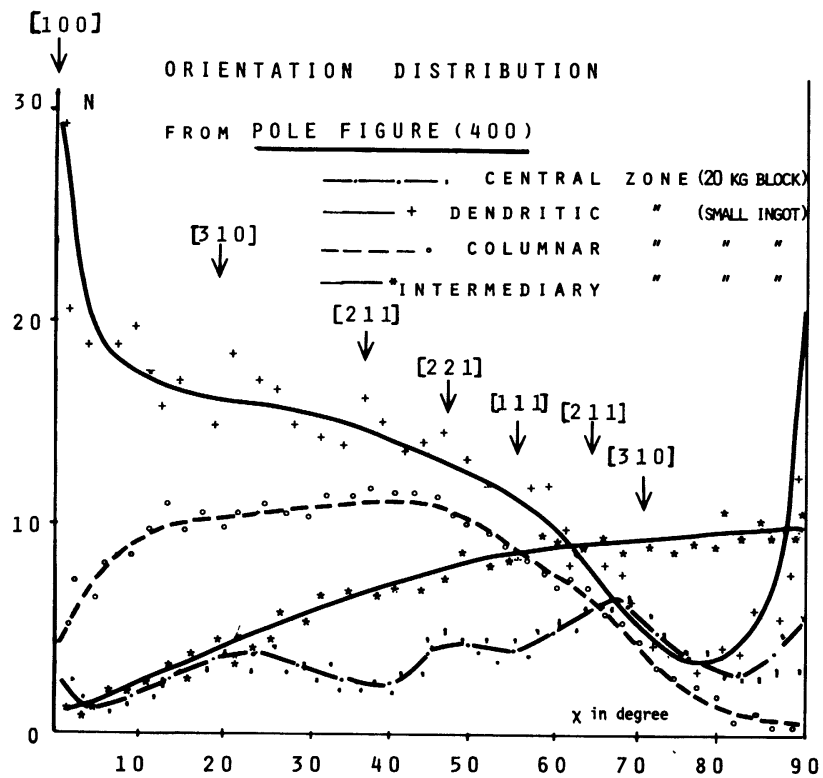

Fig. 5. - Preferential grain orientation observed in different samples. $N=$ number of grains counted for a normalized pole density $d \geqslant 1$ a sample volume $=1 \mathrm{~cm}^{3}$ and a $\chi$ step : $\Delta \chi=1^{\circ}$ (the arrows indicate approximate orientations with respect to the growth axis).

The preferential grain orientation is shown in figure 5 where the number of grains which diffract with a normalized pole density $\geqslant 1$ is reported as a function of the $\chi$ polar angle.

The size distribution is represented by the curves :

$$
\log \left(n_{i} / \Delta v_{i}\right)=f \mid \log \left(v_{i} \text { moy }\right) \mid
$$

where $n_{i}$ is the number of grains which have a volume equal to $v_{i}$ moy $\pm \Delta v_{i} / 2$ in $1 \mathrm{~cm}^{3}$ sample $\left(\Delta v_{i}\right.$ is equal to 0.02 or $0.04 \mathrm{~mm}^{3}$ ) (see Fig. 6).

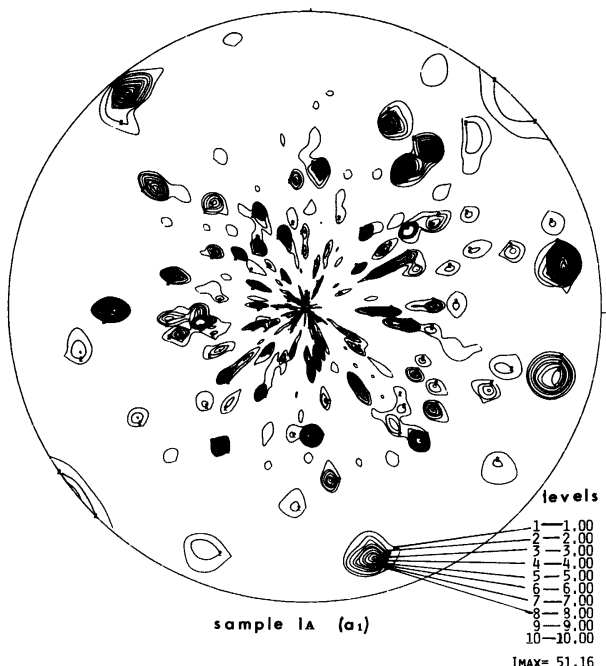

a)

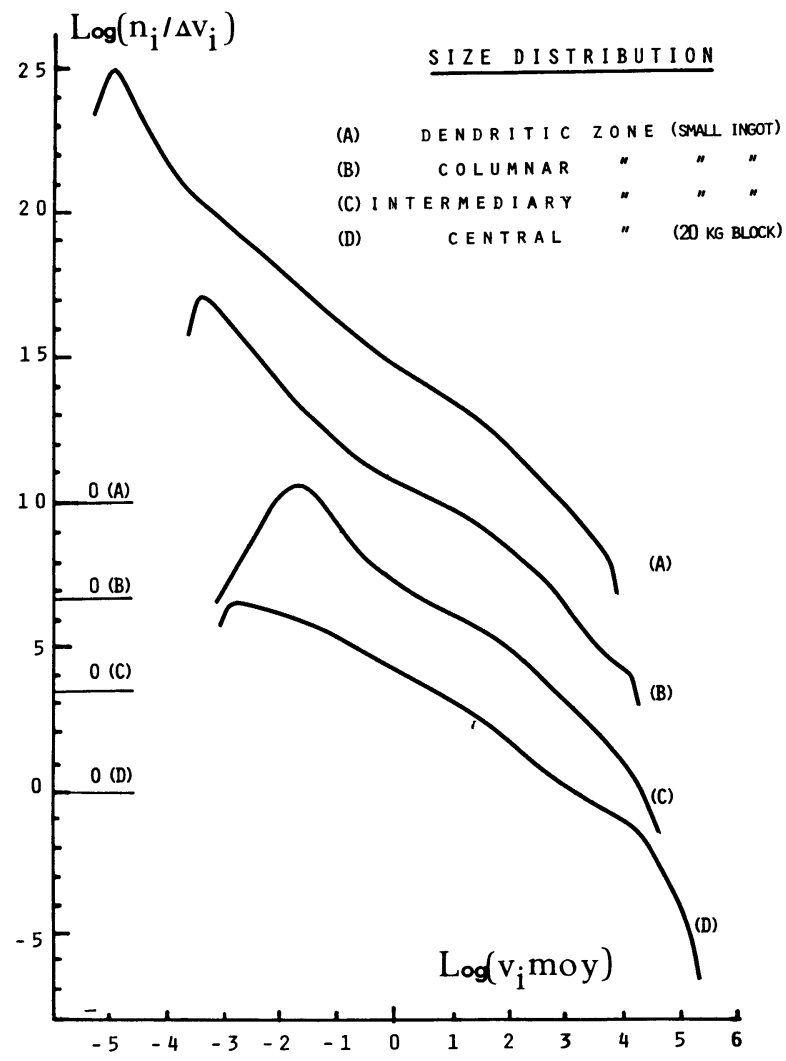

Fig. 6. - Size distribution in one $\mathrm{cm}^{3}$ of material.

For large grains $(d \geqslant 50)$ or crystallites regrouped about a given orientation, the «ideal orientations » were determined from the P.F. (400) and (111) and controlled with the P.F. (220). Particular orientations are not observed for the larger crystallites.

Full texture analysis, with series expansion cut off at $\lambda_{\max }=34$, has been performed up to O.D.F., for

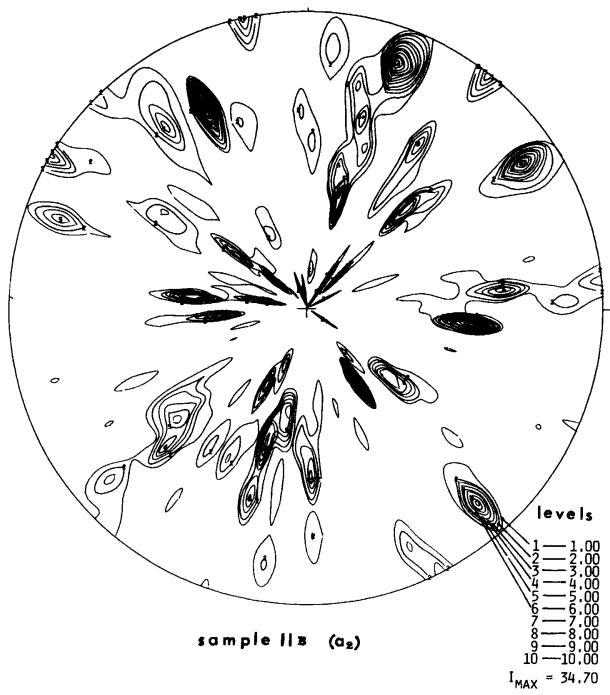

Fig. 7. - Smoothing effect observed on the pole figure (400) - a) raw data; as measured but 10 successive data obtained in $\Delta \chi$ scan are regrouped and the result allocated at the barycentre $a_{1}$ ) sample $I_{A} ; a_{2}$ ) sample $\mathrm{II}_{\mathrm{B}}$, - b) smoothed by Welch's routine : $\mathrm{b}_{1}$ ) $\left.\phi_{0}=5^{\circ} ; \mathrm{b}_{2}\right) \phi_{0}=7.5^{\circ}$, - c) smoothed by Esling's routine $\mathrm{c}_{1}$ ) $\left.\phi_{0}=5^{\circ} ; \mathrm{c}_{2}\right) \phi_{0}=10^{\circ}$ for sample $\mathrm{I}_{\mathrm{A}} \mathrm{c}_{3}$ ) $\phi_{0}=5^{\circ} ; \mathrm{c}_{4}$ ) $\phi_{0}=7.5^{\circ}$ for sample $\mathrm{II}_{\mathrm{B}}$. (A rotation about $X X^{\prime}$ axis equal to $180^{\circ}$ marks the difference between the Esling's representation and the Welch's representation). 

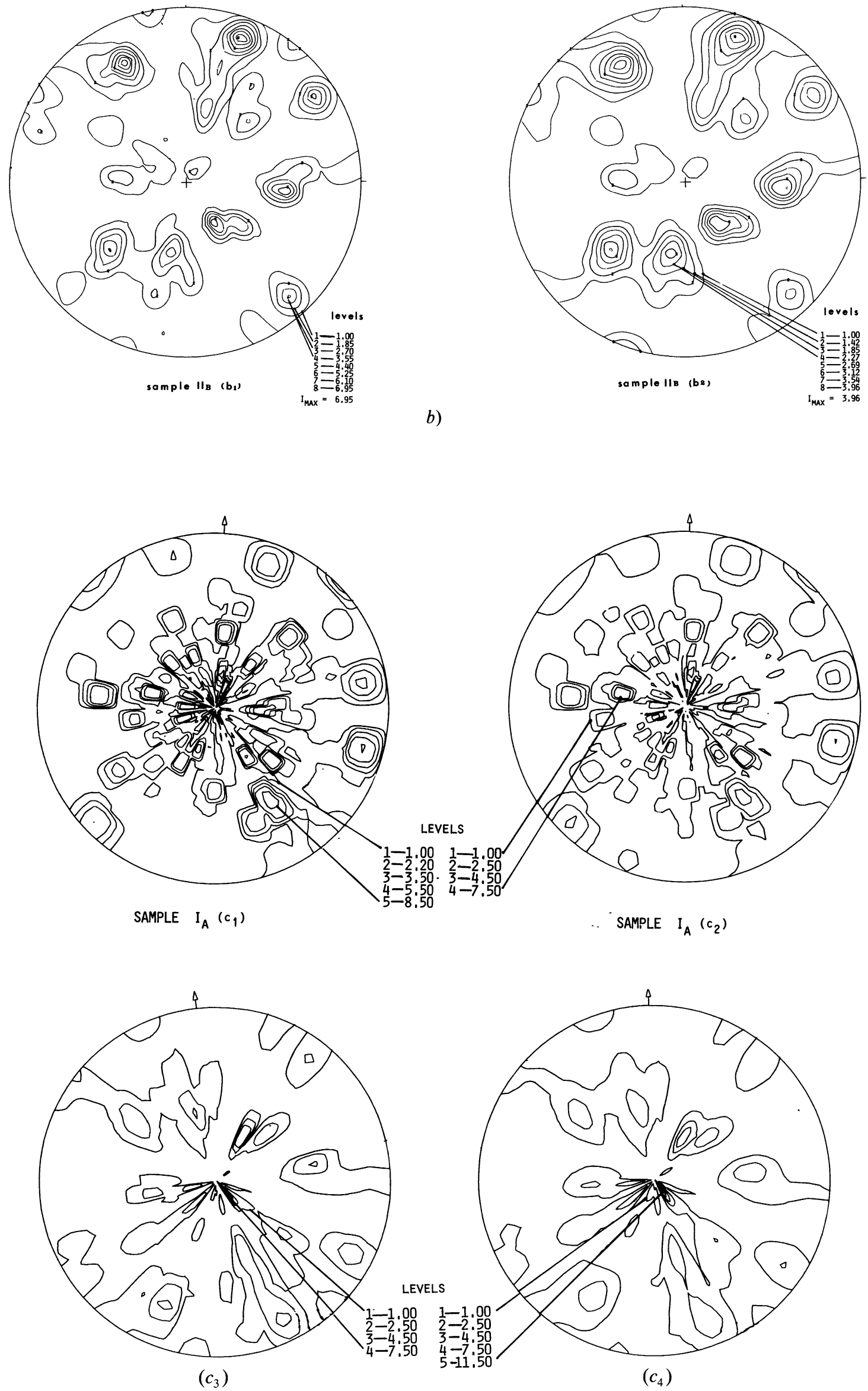

c) 
both specimens $\mathrm{I}_{\mathrm{A}}$ and $\mathrm{II}_{\mathrm{B}}$ taken in the dendritic and intermediary zones respectively. The four different pole figures are taken into account in this analysis.

The smoothing effect of increasing the half width of the Gaussian function $\left(0 \leqslant \phi_{0} \leqslant 10^{\circ}\right.$ by steps of $2.5^{\circ}$ ) was studied using both programs. We have retained the second one which gives a smaller intensity attenuation and no excessive smearing. The figure 7 demonstrates this effect on the pole figures (400) $\left({ }^{1}\right)$.

The O.D.F. are plotted (Figs. 8a, b) in $\mathrm{PHI}_{1}$ sections with steps of $20^{\circ}$ from $0^{\circ}$ to $360^{\circ}$; PHI and $\mathrm{PHI}_{2}$ vary from $0^{\circ}$ to $90^{\circ}$ on account of the cubic crystalline symmetry. The analysis of the so obtained O.D.F. sections is difficult. The material does not present a marked fiber texture like it is observed sometimes in geological samples and the «ideal orientation » number is not limited.

Nevertheless the coincidence, observed between experimental and recalculated P.F. (see Fig. 9) confirms the validity of complex O.D.F. which integrate the anisotropy characteristics correctly.

Since this work represents only a very first attempt in relating the photovoltaïc efficiency of polycrystalline silicon to its texture, we consider the fairly reasonable agreement between the recalculated P.F. (Figs. 9a, b) and the experimental smoothed ones (Figs. 7c1 to $\mathrm{c} 4$ ) as encouraging with respect to the expected precision of the three-dimensional texture analysis.

Different error criteria have been defined by various authors [14-16].

But it is also possible to evaluate more easily the calculation errors, by means of an error criterion based on the positivity default of the recalculated P.F. :

$$
\delta=\frac{\left|I_{\min }^{-}\right|}{\left|I_{\max }\right|} \times 100
$$

where $I_{\min }^{-}$is the lowest (negative) P.F. value referred to the maximal intensity. Indeed, the more the texture is sharp, the more negative values appear in the P.F. recalculated by series expansion. This criterion corresponds to the mathematical norm $L_{\infty}$ :

$$
L_{\infty}=\lim _{p \rightarrow \infty} L_{p}=\lim _{p \rightarrow \infty} \frac{1}{N}\left(\sum_{i} \varepsilon_{i}^{p}\right)^{1 / p}
$$

The error values are reported in table I.

( $\left.{ }^{1}\right)$ We draw the attention of the reader that the P.F. plot programs used in Clausthal by P. Welch [13] and those used by the authors make exploitation of the azimuthal $\Phi$ angle in a reversed sense each other, starting from a common origin $\Phi=0$ in the direction of the $X$ axis. This leads to a symmetry operation resulting in a rotation of $\pi$ around the $X$-axis, in order to compare the respective P.F. plots.

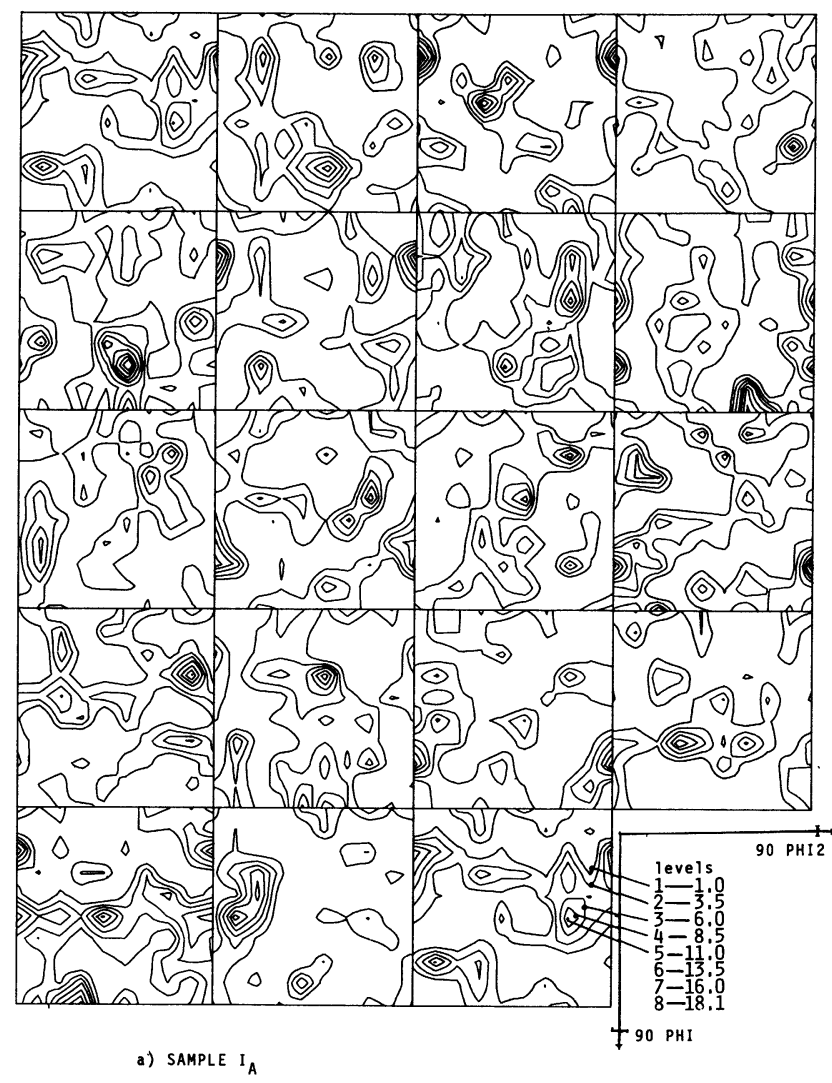

a)

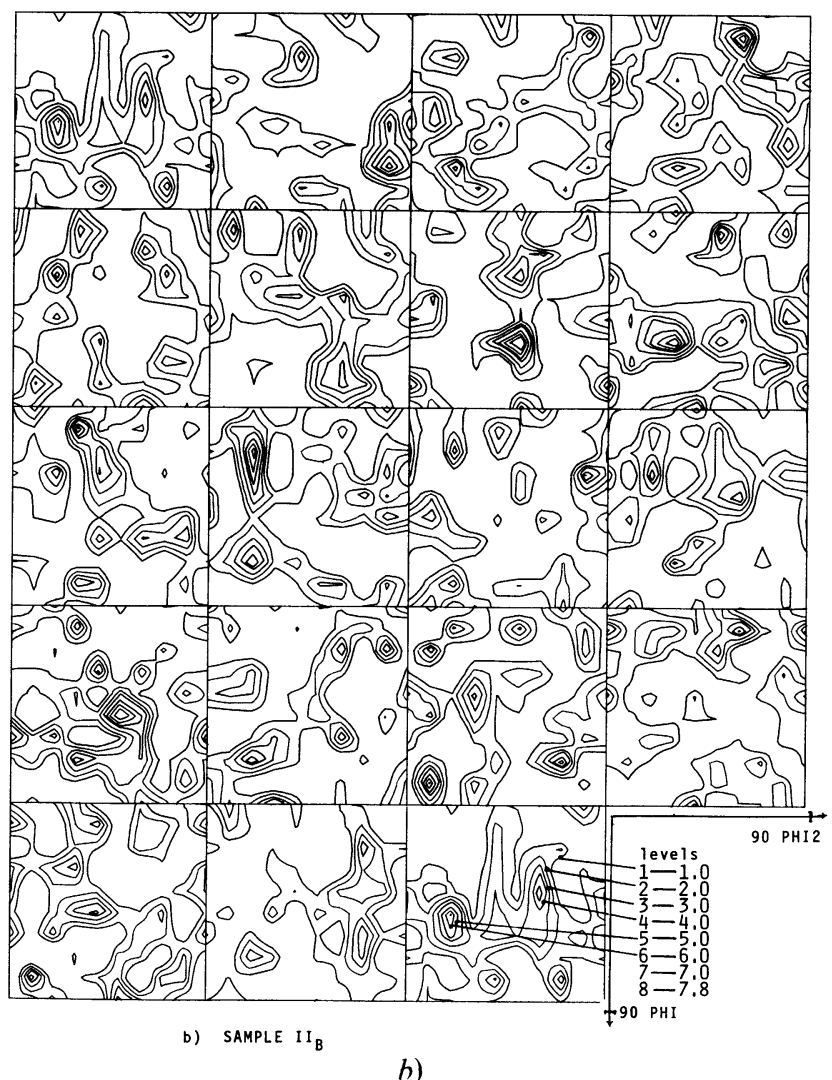

b)

Fig. 8. - Computed O.D.F. plotted in $\mathrm{PHI}_{1}$ sections with $\Delta \mathrm{PHI}_{1}=20^{\circ}$ through Euler space - intensity levels are reported a) sample $I_{A}$; b) sample $\mathrm{II}_{B}$. 


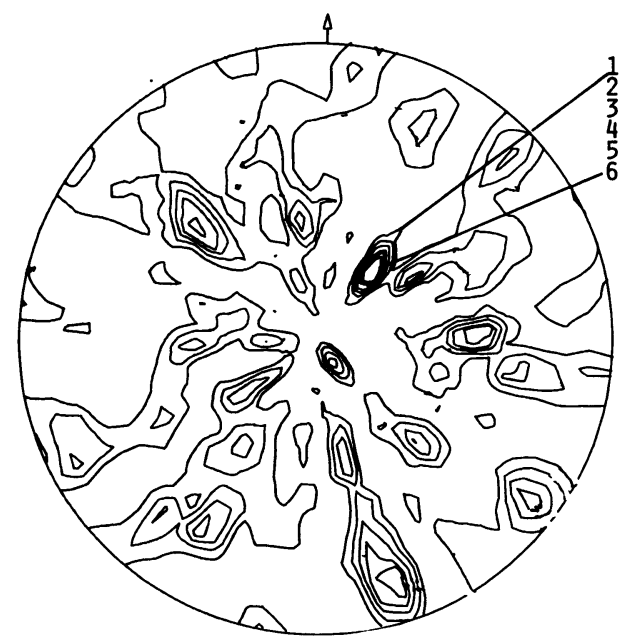

a)

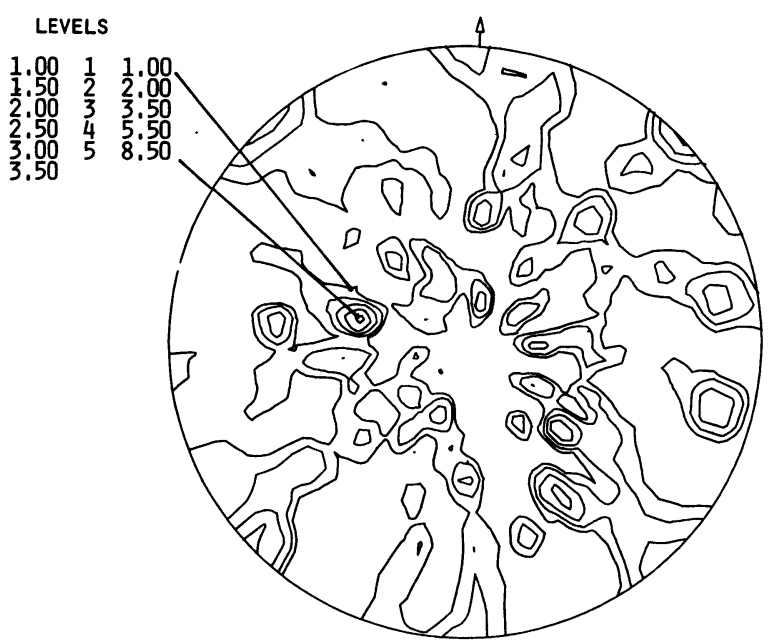

b)

Fig. 9. - Recalculated Pole Figure (400) from smoothed values obtained with a) $\phi_{0}=7.5^{\circ}$ with sample $\mathrm{II}_{\mathrm{B}}$; b) $\phi_{0}=10^{\circ}$ with sample $\mathrm{I}_{\mathrm{A}}$.

TABLE I.

\begin{tabular}{|c|c|c|c|c|c|c|c|c|c|}
\hline Sample $\downarrow$ & P.F. $\rightarrow$ & \multicolumn{2}{|c|}{ (111) } & \multicolumn{2}{|c|}{ (220) } & \multicolumn{2}{|c|}{ (400) } & \multicolumn{2}{|c|}{ (113) } \\
\hline $\begin{array}{lll} & \cdot & I_{\max } \\
\mathrm{I}_{\mathrm{A}} & I_{\min }\end{array}$ & $\delta \%$ & $\left.\begin{array}{r}5.96 \\
-2.11\end{array}\right\}$ & 35.0 & $\begin{array}{r}13.23 \\
-\quad 3.34\end{array}$ & 17.6 & $\left.\begin{array}{r}9.91 \\
-1.60\end{array}\right\}$ & 16.0 & $\left.\begin{array}{r}6.58 \\
-1.24\end{array}\right\}$ & 18.7 \\
\hline $\begin{array}{ll} & I_{\max } \\
\mathrm{II}_{\mathrm{B}} & I_{\min }\end{array}$ & $\delta \%$ & $\left.\begin{array}{r}3.97 \\
-0.62\end{array}\right\}$ & 15.5 & $\left.\begin{array}{r}2.85 \\
-\quad 0.77\end{array}\right\}$ & 27.0 & $\left.\begin{array}{r}4.80 \\
-0.66\end{array}\right\}$ & 13.8 & $\left.\begin{array}{r}2.21 \\
+0.11\end{array}\right\}$ & 0.0 \\
\hline
\end{tabular}

Although this criterion is quite severe, the obtained values are in the order of magnitude'to those observed in the case of metallurgical textures (at least when P.F. are measured only by X-ray diffraction). This result seems to be satisfactory at this stage of limit case of texture analysis (cf. the problems of inhomogeneities and poor statistics as exposed previously).

This criterion presents the advantage to be very easy to evaluate and represents, from the mathematical view, a lower bound to the errors.

Although the O.D.F. 'pictures appear of first sight very confusing, some differences can be pointed out for the two textures.

First, the texture of sample $I_{A}$ is much sharper than the texture of $\mathrm{II}_{\mathrm{B}}$, as it can be concluded from the comparison of the intensity levels and the texture indices $[8,10]-\left(I_{\mathrm{I}_{\mathrm{A}}}=19.1\right.$ and $\left.I_{\mathrm{II}_{\mathrm{B}}}=5.2\right)$. Moreover, the examination of (400) P.F. - (see Figs. 4a and 7a1, c1, c2) - leads to expect a partial fibre in the dendritic $I_{A}$ sample, with the crystallographic [111] axes parallel to the growth axis, which is also the projection axis of the P.F. This partial fibre is well confirmed in the Euler-space, where it is defined by the line $\left\{\mathrm{PHI}=54^{\circ}, \mathrm{PHI}_{2}=45^{\circ}\right.$, $\left.0 \leqslant \mathrm{PHI}_{1} \leqslant 2 \pi\right\}$. This fibre leads to several peak strengthenings in the O.D.F. plot, especially in the sections $\mathrm{PHI}_{1}=20^{\circ}, 80^{\circ}, 300^{\circ}, 320^{\circ}$, allowing some broadening for the peaks.

As opposed to this, the O.D.F. sections of II $_{B}$ sample do not permit a simple interpretation of the orientations relative to the growth axis. Some tendency to isotropy is shown by weak distorted contours and maximum levels inferior to those of the sample $I_{A}$.

\section{Conclusion.}

A complete quantitative description of the solidification texture can be obtained by neutron diffraction experiments for the heterogeneous silicon used in photovoltaic conversion. The use of smoothing programs allows the O.D.F. calculation. A comparison of the experimental and recalculated pole figures is a very good mean for checking the experimental data and the fitting model O.D.F. The excessive experi- 
ment time could be reduced, without resolution loss, using a continuous $\Phi$ exploration in the integration mode.

\section{Acknowledgments.}

The authors would like to thank Dr. Welch who has worked out some P.F. smoothing calculations ac- cording to his technique [12] at the University of Clausthal and Dr. Humbert and Dr. Wagner who have contributed to the O.D.F. calculations at the University of Metz. They thank the Laboratory Léon Brillouin for providing neutron diffraction facilities. This project was partially sponsored by the C.N.R.S. and the A.F.M.E.

\section{References}

[1] Fally, J. and Guenel, C., Proceedings on the International Conference of Photovoltaic Solar Energy (Cannes, France) 1980, p. 589-602.

[2] Fally, J. and Guignot, D., Poly-Micro Crystalline and Amorphous Semiconductors, MRS-meeting Strasbourg, France (1984), (edited by P. Pinard and S. Kalbitzer, Edition de Physique Colloque MRS) 1984, p. 199-206.

[3] Photowatt S.A., 6, rue de la Girafe, 14002 Caen Cedex, France.

LAY, P., Thèse Docteur Ingénieur, Université de Caen (janvier 1987).

[4] Andonov, P., Revue Phys. Appl. 17 (1982) 657-679.

[5] MARDON, J. P., Thèse $3^{\mathrm{e}}$ cycle, Université Paris-Sud Orsay (1977).

[6] Dervin, P., Utilisation des faisceaux de neutrons en métallurgie, Ecole d'Aussois (édité par le Commissariat à l'Energie Atomique) 1981.

[7] Couterne, J. C. and Cizeron, G., J. Appl. Cryst. 4 (1971) 461-472.
[8] Bunge, H. J., Mathematische Methoden der Texturanalyse (Akademie Verlag, Berlin) 1969.

[9] Roe, R. J., J. Appl. Phys. 36 (1965) 2024.

[10] Bunge, H. J. and Esling, C., Quantitative texture analysis, Deutsche Gessellschaft fur Metallkunde (1982).

[11] Dervin, P., Thèse Docteur Ingénieur, Université Paris-Sud Orsay (1978).

[12] Welch, P. I., Proceedings of the seventh International Conference on Texture of Materials (Noordwijkerhout-Holland) 1984, p. 863-868.

[13] WelCh, P. I., Private communication University Clausthal, RFA:

[14] Dervin, P., Pernot, M. and Penelle, R., J. Appl. Cryst. 13 (1980) 494.

[15] Humbert, M., Wagner, F. and BARo, R., Texture of Crystalline Solids 3 (1978) 27-36.

[16] Matthies, S., Aktuelle Probleme der Quantitativen Texturanalyse (Z.K. publikationen Dresden, RFA) 1982. 